\title{
Patient Collapse after Medical Round: Rupture of Infected Kidney Following Physical Exam
}

\author{
Mohamad Mostafa Habli ${ }^{1 *}$, Oussama Hassan ${ }^{1}$, Sirine Omar Ahmad ${ }^{2}$ and Najat Issa Joubran-Fares ${ }^{3}$ \\ ${ }^{1}$ Department of Nephrology, Saint George Hospital, University of Balamand, Lebanon \\ ${ }^{2}$ Faculty of medicine, Rafic Hariri University Hospital, Lebanese University, Lebanon \\ ${ }^{3}$ Department of Nephrology, Saint George Hospital University Medical Center, University of Balamand, Lebanon
}

Submission: May 11, 2017; Published: June 19, 2017

*Corresponding author: Mohamad Mostafa Habli, Department of Nephrology, Saint George Hospital, University of Balamand, Lebanon, Tel: 0096170565137; Email:dr_mh_habli@hotmail.com

\begin{abstract}
Introduction: Kidney rupture is a rare complication of external trauma.The spontaneous rupture of a kidney is even more rare. The presence of several risk factors such as pyelonephritis, hydronephrosis or nephrolithiasis could be the underlying etiology.

Case Presentation: Herein, we report a case of a 70-year old male who was admitted for management of left sided obstructive pyelonephritis and hydronephrosis. During hospitalization, traumatic kidney rupture occurred following physical examinations by group of medical students during the morning medical round.

Conclusion: “Lenk's triad”, onset of flank pain, tenderness, and symptoms of internal bleeding, in a patient with risk factors for kidney ruptures should raise the suspicion of this uncommon life threatening event. Patient at risk should be evaluated by renal imaging prior to physical exam.
\end{abstract}

Keywords: Kidney rupture; Lenk's triad; Pyelonephritis; Physical examination

\section{Introduction}

The "Lenk's triad", defined by acute onset of flank pain, tenderness and symptoms of internal bleed, should raise the suspicion of spontaneous kidney rupture in the absence of any trauma or surgery [1]. Several cases of spontaneous rupture of the kidney dating back to 1924 have been reported [2]. Parenchymal rupture is rare and usually complicated an underlying situation or disease such as pregnancy, malignancy (renal cell carcinoma), pyelonephritis, infected renal cyst, and obstructive stone and hydronephrosis [3-6]. However some reports dating back to the early fifties, discussed the issue of spontaneous kidney rupture with no underlying etiologies [2]. In 1966, Valtonem et al. [7] reported 4 cases of spontaneous rupture in previously normal appearing kidneys [7]. Very recently, a rupture of renal angiomyolipoma due to hard physical examination has been reported [9]. Herein, we report on a case of kidney rupture that occurred after physical examinations by a group of medical students in a patient with pyelonephritis.

\section{Case Presentation}

A 70-years old male patient was admitted for flank pain, and chills. Patient has a history of transitional cell carcinoma of the bladder that was treated by cystectomy and neo-bladder formation. Initial surgery was complicated by left ureteral stricture causing atrophic left kidney and impaired kidney function, i.e. serum creatinine level of $1.5 \mathrm{mg} / \mathrm{dL}$ and estimated glomerular filtration rate at $49.18 \mathrm{ml} / \mathrm{min} / 1.73 \mathrm{~m} 2$ ( according to MDRD equation).

History goes back to the same day of presentation, when he started complaining of left flank pain, radiating to the groin area, associated with chills, diaphoresis and high grade fever of $40{ }^{\circ} \mathrm{C}$. At admission, the patient was hypotensive with a mean arterial blood pressure of $70 \mathrm{mmHg}$. Urine analysis revealed a white cell count of $160 \mathrm{cell} / \mathrm{mm}^{3}$ and red blood cells of $42 \mathrm{cell} / \mathrm{mm}^{3}$. Patient has also elevated white blood count was $19200 \mathrm{cell} / \mathrm{mm}^{3}$ and elevated acute phase reactants. C-reactive protein was elevated at $18 \mathrm{mg} / \mathrm{dL}$ upon admission Empirical treatment with IV hydration of around 3.5L of normal saline and wide spectrum IV antibiotics (dose of Amikacin 1g IVD) was initiated. After clinical stabilization of the patient, CT scan abdomen and pelvis (without contrast) was done showing bilateral hydronephrosis, more on the left with enlarged calyx and thin kidney cortex (Figure 1). Urologist and interventional radiologist were urgently consulted 
for making decision on surgical or radiological intervention. Urolgist decided on nephrostomy on the next day as the patient clinical condition stabilized.

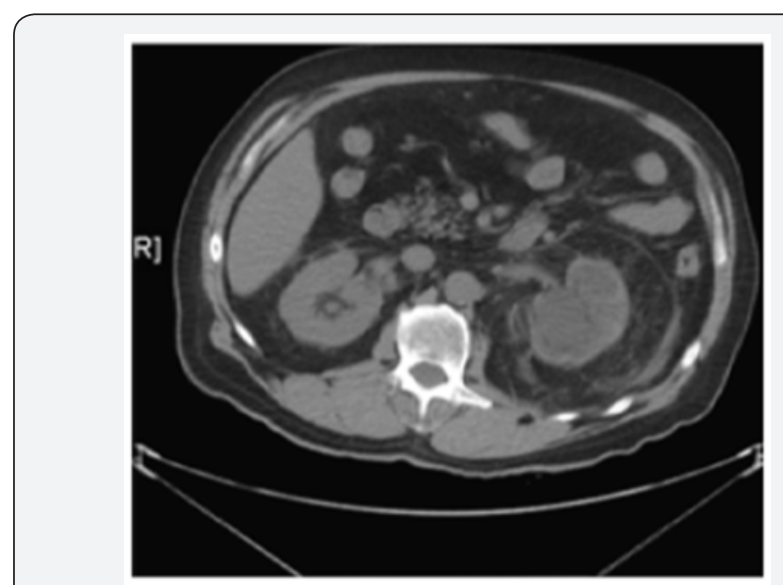

Figure 1: CT scan of the abdomen upon hospitalization: left hydronephrosis, atrophied kidney, enlarged calyx and thin kidney cortex.

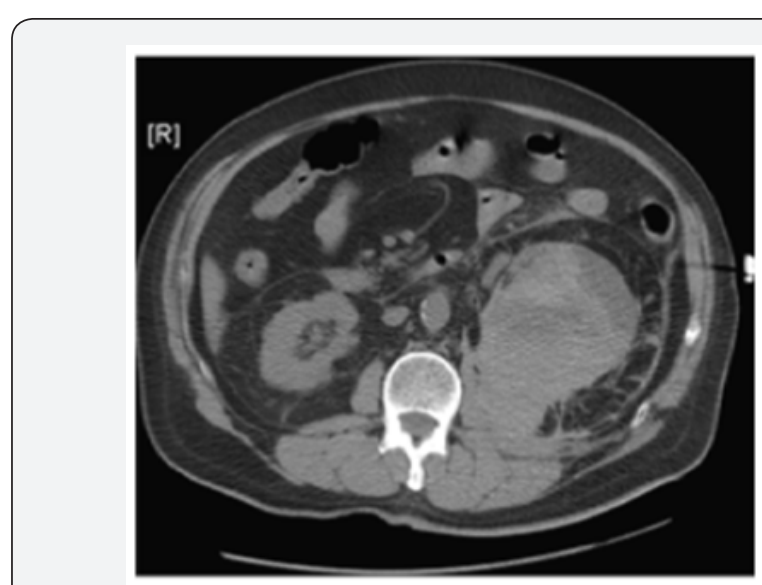

Figure 2: Follow up CT scan after physical examination: edematous left kidney surrounded by hematoma.

The patient was admitted to the intensive care unit for management of sepsis/pyelonephritis - obstructive in etiology. The patient was hemodynamically stabilized with a mean arterial blood pressure of $100 \mathrm{mmh}$ not necessitating inotropes. The second day post admission, the patient was examined by the group of medical student during the morning medical round for costovertebral angle tenderness. Five minutes after examination, the patient started to complain of severe left flank pain grade 9/10 not relieved by pain killers. Clinical examination revealed a large mass on the left side of the abdomen with severe pain upon palpation. Urgent abdominal CT-scan showed a ruptured left kidney with hematoma surrounding it (Figure 2). On the spot, patient was transferred to operation block for radical nephrectomy. During the surgery, a large perinephric hematoma was identifies and large amount of purulent discharge was drained. Patient underwent nephrectomy.

\section{Discussion}

The entity of non traumatic spontaneous kidney rupture is rare. The kidney rupture is divided into two entities: kidneys with pathological changes and rupture of an apparently normal kidney. The majority of kidney ruptures are associated with an underlying etiology.

In the present case, there were several risk factors for kidney rupture. First, our patient had an obstruction due to the ureteral stricture that was responsible for hydronephrosis. Second, he had severe pyelonephritis that had led to a severe sepsis requiring an important hydration. The hydration with normal saline aiming to stabilize the septic patient had probably exacerbated the hydronephrosis. Furthermore, our patient had an atrophic kidney with a thin kidney cortex, and therefore a more vulnerable kidney, especially when infected. In summation, the aforementioned risk factors caused an increase in the intra capsular pressure in the left kidney and we speculate that the clinical examination of the patient was the catalyst that added the extra force needed to initiate the kidney rupture (Figure 3). However, we may wonder if there was a role for a percutaneous nephrostomy in our patient. The principle indication for nephrostomy is the relief of urinary obstruction in the presence of hydronephrosis. Complications related to the procedure are not common. But due to the presence of a huge collection in the kidney, manipulation can exacerbate the urosepsis. Consequently, the procedure in our patient was delayed. But was it possible to prevent the kidney rupture if a nephrostomy was placed?

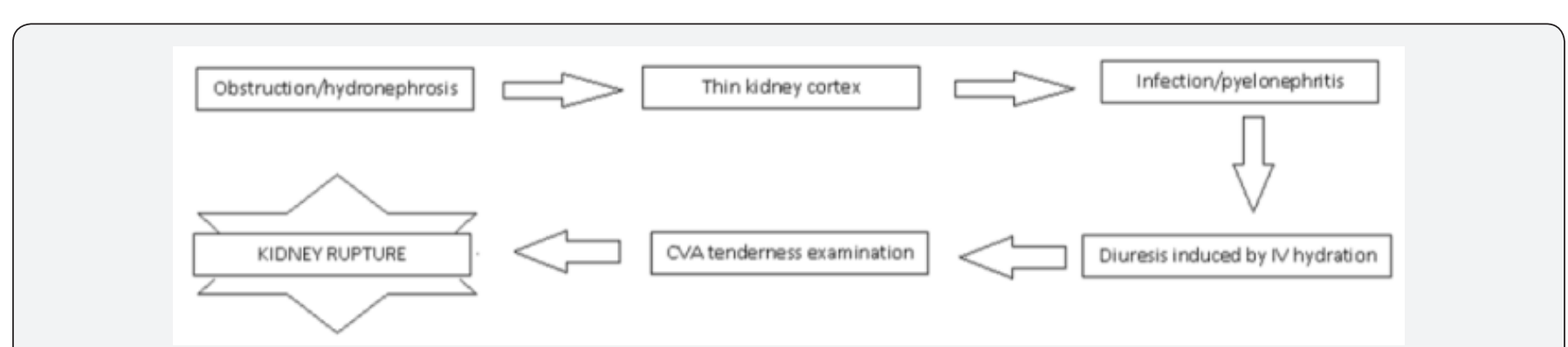

Figure 3: Potential sequence of events leading to spontaneous kidney rupture. 


\section{Conclusion}

Spontaneous kidney rupture can occur if the favorable environment is present. Although condition is very rare, but medical team including students and residents should be aware of this possible complication in high risk patients. Having a patient with the risk factors and presenting with the lenk's triad, should trigger a more appropriate approach and smooth physical exam aiming to avoid the complication of this rare life threatening entity. Surgical or radiological intervention should not be postponed in septic patients, as delay may expose patients to clinical deterioration.

\section{References}

1. Koo V, Duggan B, Lennon G (2004) Spontaneous rupture of kidney with peri-renal hematoma: a conservative approach. Ulster Med J 73(1): 53-56.

2. Murphy G, Harney C (1951) Spontaneous rupture of the normal kidney parenchyma. Ann Surg 134(1): 127-130.

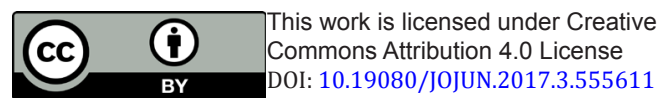

3. Vaidyanathan S, Hughes P, Oo T, Soni B (2008) Spontaneous rupture of an infected renal cyst and external drainage through a lumbar surgical scar in a male patient with cervical spinal cord injury: a case report. J Med Case Rep 2: 154.

4. Szentgyorgyi E, Kondas J, Varga Sz, Lörinczy D, Regös I, et al. (1994) Spontaneous Rupture of the Kidney: A Report on 5 Cases. Int Urol Nephrol 26(2): 133-140.

5. Cavoli G, Bono L, Totorici C, Ferrantelli A, Giammarresi C, et al. (2012) Spontaneous kidney rupture in a patient on chronic hemodialysis. Indian J Nephrol 22(2): 145-146.

6. Lo K, Ng C, Wong W (2007) Spontaneous rupture of the left renal collecting system during pregnancy. Hong Kong Med J 13: 396-398.

7. Valtonem E (1966) Spontaneous rupture of an apparently normal kidney; some criticism concerning the diagnosis. Br J Urol 38(5): 484 487.

8. Tarrass F, Benjelloun M, Medkouri G, Hachim K, Gharbi MB, et al. (2007) Spontaneous kidney rupture-an unusual complication of Wegener's granulomatosis. Nephrol Dial Transplant 22(1): 280.

9. Zengin S, Al B, Yildirim C, Oktay M, et al. (2012) Rupturing of renal angiomyolipoma due to physical examination. BMJ Case Reports.

\section{Your next submission with Juniper Publishers} will reach you the below assets

- Quality Editorial service

- Swift Peer Review

- Reprints availability

- E-prints Service

- Manuscript Podcast for convenient understanding

- Global attainment for your research

- Manuscript accessibility in different formats

( Pdf, E-pub, Full Text, Audio)

- Unceasing customer service

Track the below URL for one-step submission https://juniperpublishers.com/online-submission.php 